\title{
Foreword to the special issue on the "Electronic Structure: Principles and Applications (ESPA 2016)" Conference
}

\author{
Manuel F. Ruiz-López ${ }^{1}$ Juan Andrés ${ }^{2}$
}

Published online: 20 October 2017

(c) Springer-Verlag GmbH Germany 2017

The Electronic Structure Principles and Applications (ESPA) series of Conferences began in 1998. The meetings take place every 2 years in Spain and cover the most important fields of Theoretical and Computational Chemistry (TCC). They represent a unique opportunity to show the latest advances in this discipline and related areas as well as an excellent forum to exchange knowledge and share ideas within the international community of theoretical and computational chemists. The ultimate goal is to promote the development of fundamentals, methods, techniques and applications, but at the same time to transfer scientific discoveries to professionals in the sector.

ESPA 2016 took place in Castellon, at the Paranimf of the University Jaume I, close to the Mediterranean see, from June 28 to July 1, 2016. Prior to the start of the congress, the fifth biannual workshop of the Erasmus Mundus Master's program and Doctorate in Theoretical Chemistry and Computational Modeling was held. The organizers of the congress tried to achieve the following objectives: (1) to review major current developments and trends in TCC, (2) to create an open and friendly atmosphere encouraging

Published as part of the special collection of articles derived from the 10th Congress on Electronic Structure: Principles and Applications (ESPA-2016).

Manuel F. Ruiz-López

manuel.ruiz@univ-lorraine.fr

Juan Andrés

andres@qfa.uji.es

1 SRSMC, University of Lorraine, CNRS, BP 70239, 54506 Vandoeuvre-lès-Nancy, France

2 Departamento de Química Física y Analítica, Universitat Jaume I, Avda. Sos Baynat s/n, 12071 Castelló de la Plana, Spain scientific and technological discussions between all the participants, from both public and private institutions, and (3) to incite students and young researchers to participate and present their research work. Four main topics were covered: (1) theory (methods and foundations), (2) material sciences, (3) chemical structure and reactivity, and (4) environmental effects and modeling.

ESPA 2016 brought together more than 250 participants from more than 30 different countries. The scientific program of the Conference included 9 plenary lectures, which were assigned to highly reputed scientists, and a large number of cutting-edge communications distributed in 45 oral presentations and 185 posters. The social program included a visit on Wednesday 29th June to Peñíscola, the historical city known for being the residence of Pope Luna during the Western Schism. Peñíscola is located in the Mediterranean coast to the north of the province of Castellón. The Gala dinner took place in the Restaurant Aqua at Hotel Luz in Castellón, on Thursday 30th, where awards were presented to the best ESPA2106 poster communications.

The present topical collection of papers published in Theoretical Chemistry Accounts is a compilation of some of the research works presented at ESPA 2016. As the guest editors of this special issue, we have tried to assemble a series of contributions that reflect the diversity of ongoing work made by different groups in the field. The manuscripts illustrate the enormous progress made in the last years in the fields of theoretical chemistry, molecular modeling and atomistic simulations. Such a progress has been made possible thanks in part to the spectacular advancements achieved in computers technology but also to outstanding efforts made to develop the theory and explore new concepts. Such efforts need to be continued in the era of peta and exascale supercomputing and should include rethinking existing algorithms and software, implementing efficient tools for the 
treatment of big data as well as machine learning techniques, and considering opportunities offered by cloud computing frameworks.

The topical collection of papers related to ESPA 2016 includes research works in a variety of fields: theory, models and methods, prediction and analysis of spectroscopic and other molecular properties, chemical reactivity, materials, biological systems, environmental effects. The contents therefore provide an illustration of the most recent developments in theoretical chemistry, offering a broad perspective of the field as well as some future trends.
Before concluding this brief foreword, we would like to express our gratitude to all the authors who contributed to this topical collection, and to the referees for taking time to review the manuscripts and their valuable comments and suggestions. Finally, we want to warmly thank the Editorsin-Chief of Theoretical Chemistry Accounts, Dr. Ilaria Ciofini and Prof. Carlo Adamo, for their confidence and support along the editing process.

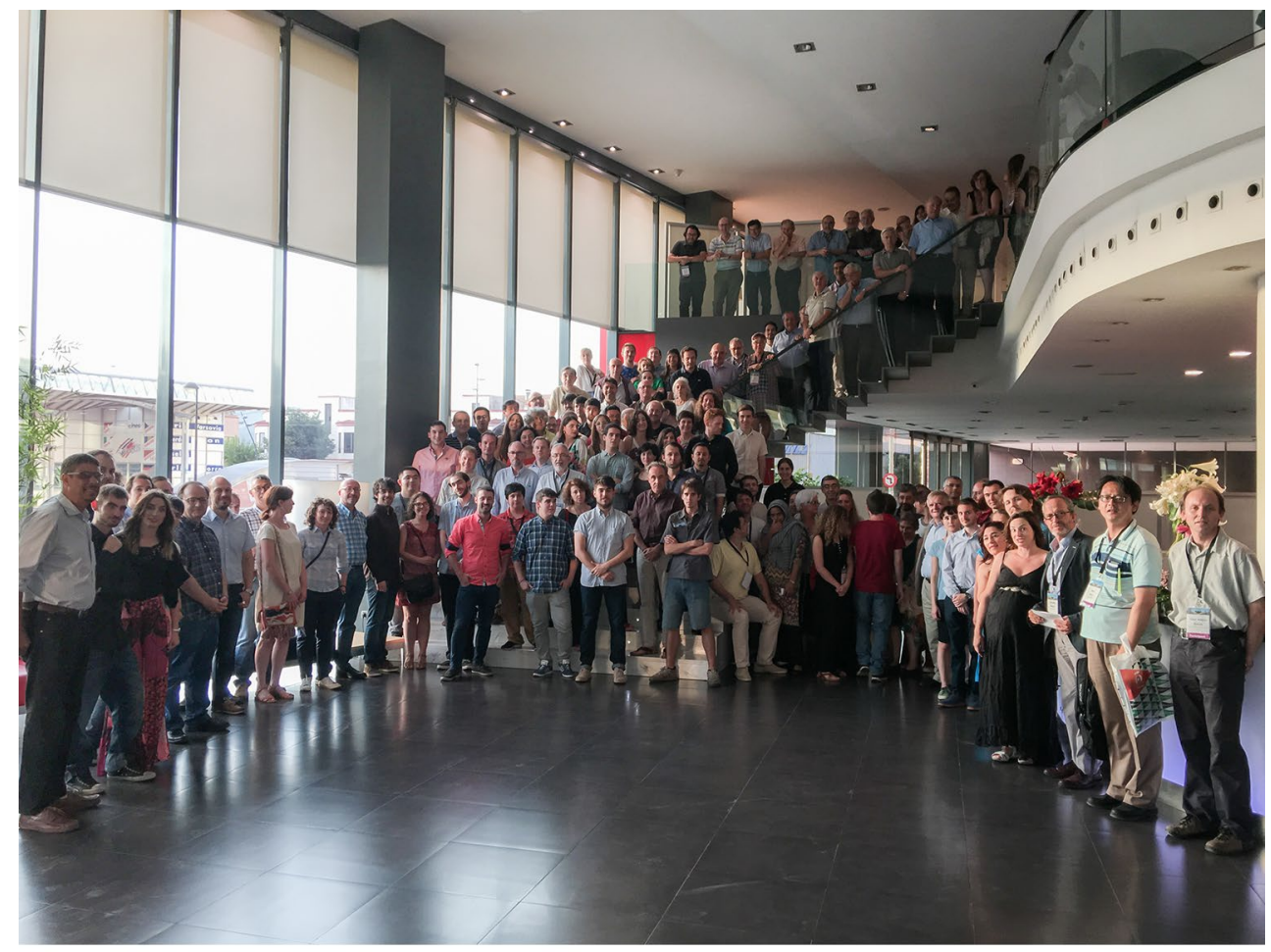

ESPA 2016 Conference group photo 